\title{
Consolidation of word sequences as a function of rehearsal time and contextual constraint'
}

\author{
MICHAEL J. A. HOWE \\ UNIVERSITY OF SHEFFIELD, ENGLAND
}

This study aimed to examine the effects of contextual constraint (CC) in short-term memory for words. Twenty four Ss read and then rehearsed lists of 6 words which were either random or second-order approximations to English. They carried out a subtracting task before attempting recall of each list. Recall varied directly with time available for rehearsal (0,3 and $6 \mathrm{sec}$. being used). At all rehearsal times constrained sequences were better recalled than randomly ordered word lists. A construction-at-recall explanation is not entirely satisfactory, and it is suggested that CC also affects the way in which lists are stored.

What underlies the observed effects of contextual constraint $(\mathrm{CC})$ on recall of word lists (Miller \& Selfridge, 1950, confirmed by e.g., Marks \& Jack, 1952; Sharp, 1958; Richardson \& Voss, 1960)? CC may have influence at the time of recall, when Ss can "construct" lists (Deese, 1961), basing their guessing on prior knowledge of the language, and lower the thresholds at which decisions can be made about the correctness of items-to-be-recalled by checking against such knowledge. The question is whether the effects of CC occur solely at this time, or whether it affects recall by influencing also the previous storage of the word lists. An approach to this problem is to observe the effects of rehearsal of word lists differing only with respect to $\mathrm{CC}$. One would not expect length of rehearsal period greatly to influence the success of strategies at the time of recall. On the other hand, differences in the way word sequences are stored might well be reflected in correct recall of lists when time available for rehearsal is varied.

The dependent variable in this experiment is the resistance of word sequences which Ss are remembering to a distracting task. Such resistance, or consolidation, is measured by scoring the recall of lists by Ss after they have performed an interfering task. Rehearsal succeeded the presentation of 6-word lists (i.e., the longest lists for which recall by English undergraduates immediately after presentation or during the rehearsal period is rarely imperfect). Then followed an additional task, after which recall was tested.

Method

Twenty four 6-word lists were taken from the second order approximations to English used by Taylor \& Moray (1961). These will be called 'B lists.' The words constituting these lists were chosen at random to make a further 24 lists of 6 words each ('A lists'). For the interference task Ss had to subtract by sevens from a 3-digit number. They read aloud the original number (x), and said the subsequent 3 residual numbers $(x-7, x-14$, $x-21$ ), simultaneously writing them down. Ss received a new number for each trial, within which all Ss in a group were given different numbers. Each commencing number for an interfering task was printed on the sheet of paper used by an $S$ for subsequent recall of the word sequence.

The 24 Ss were randomly assigned to 3 approximately equal groups. They were each shown 48 lists, in 6 batches of 8 . There were 3 values of the rehearsaltime variable, 0,3 and 6 sec., and within batches the same value was used with all lists, Ss all seeing 2 batches of 8 lists coupled with each rehearsal-time. Orders of rehearsal-time batches were balanced between groups. Within each batch there were $4 \mathrm{~A}$ lists and $4 \mathrm{~B}$ lists, ordered randomly except that no runs of over 3 were included. Lists were projected for $3 \mathrm{sec}$. onto a large screen. Ss were told to watch each list until it disappeared, and then rehearse silently until a red lamp, placed just below the screen, was illuminated. In the no-rehearsal condition this coincided with the disappearance of the list. The lamp was the cue for Ss to start the interference task, on completion of which written recall was attempted. Ss had to write from left to right, above 6 printed dashes on recall sheets, so that position as well as order of words were as originally presented. About $30 \mathrm{sec}$. elapsed between the start of the interference task after one list and the projection of the next list. For practice, Ss had 4 trials of the interference task alone, followed by 9 trials of the full experimental procedure. Scoring was by ordered recall. To be correct a word had to be recalled in the original position in a list. $E$ also counted items correct regardless of position, but the results obtained by this method of scoring are not included here. They contained no intercondition differences to the results measured by ordered recall.

\section{Results}

Figure 1 shows the average number of words correctly recalled of both types of 6-word lists for all rehearsal times. B lists are better recalled than A lists at all values of rehearsal time $(p<.001)$. With both types of list more is recalled when 6 sec. rehearsal precede the interference task than where no time is allowed for rehearsal $(p<.001$ for B lists, $<.01$ for A lists). There is clearly no interaction between the effects of type of list and length of time for rehearsal.

If the distribution of errors between serial positions in A lists is compared with the distribution to be expected if the errors in A and B lists were distributed 


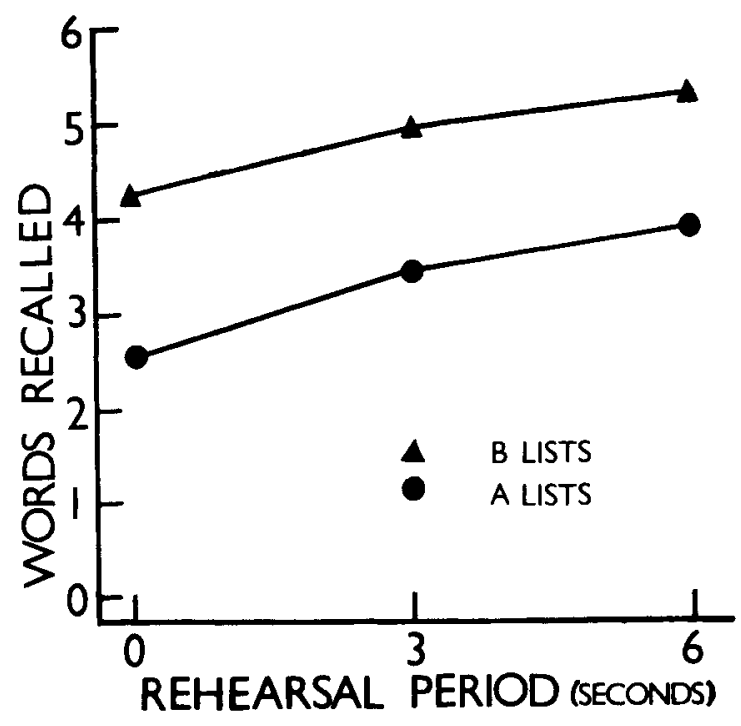

Fig. 1. Average number of words correctly recalled per list as a function of contextual constraint and rehearsal time.

identically among serial positions within conditions, there is no significant difference in shapes of distributions between $A$ and $B$ lists. $\left(\chi^{2}=8.61(5)\right.$ for difference between $\mathrm{A} 0$ and $\mathrm{B} 0 ; 3.34$ (5) for $\mathrm{A} 3$ and $\mathrm{B} 3 ; 4.96$ (5) for $A 6$ and B6. For all of these $p>.1$.) Averaged over all rehearsal times, the percentage of total errors occurring at each serial position never differs between list types by more than $2.1 \%$. Total errors (out of 576) for positions 1-6 respectively are $153,205,267,308,259$, and 180 in recall of A lists, and $62,83,109,131,113$, and 93 in B lists.

\section{Discussion}

Retention of both random and constrained lists is less affected by a distracting task when time is allowed for rehearsal. The lack of an interaction between the effects of $\mathrm{CC}$ and rehearsal time should be interpreted with caution. An increase in recall difference after rehearsal would be a reasonable indication that $B$ lists are more efficiently stored than $A$ lists, although there is a complication in that the effect as well as the result of $\mathrm{S}$ performing an interfering task is not necessarily independent of prior level of retention. The absence of any increase in recall differences does not preclude a difference in storage efficiency. To maintain a constant differential in amount recalled over various rehearsal times more B list items than A list items would be required to profit by rehearsal in gaining resistance to the subsequent interfering task. Further, the assumption that rehearsal would magnify differences in resistance to interference due to sequences being stored differently could be wrong.

A more satisfactory answer to the question of whether a construction-at-recall account alone is sufficient to explain the superiority in recall of constrained lists is obtained by a serial position analysis of errors. If the difference is largely due to construction, the probability of the item presented nth in a sequence of 6 words being recalled correctly, given that item $n-1$ is correct (where $6 \geqslant n \geqslant 2$ ) should be higher in $B$ lists than in A lists. This is not the case in the present experiment, interposition distribution of errors being very similar for $A$ and $B$ lists. The related fact that words presented in the first postion in lists are better recalled when followed by $B$ than by $A$ sequences cannot be explained by a construction-at-recall hypothesis, the ratio of errors in A lists to B lists for the word presented first being 2.5:1, which is higher than the corresponding ratio for any other serial position. In fact, there is no definite evidence that construction-at-recall is a cause of the greater recall of constrained than random sequences in the present experiment. The suggestion that the effects of $\mathrm{CC}$ on word recall scores are due to its affecting materials in store prior to recall, as well as any construction-at-recall effect, is supported by findings of Lachman \& Tuttle (1965), who reached a similar conclusion by a study in which construction-at-recall was precluded by testing recognition, one word at a time.

\section{References}

Deese, J. From the isolated verbal unit to connected discourse. In C. N. Cofer (Ed.), Verbal learning and verbal behavior. New York: McGraw-Hill, 1961. Pp. 11-31.

Lachman, R., \& Tuttle, A . V. Approximations to English (AE) and short-term memory: construction or storage? J. exp. Psychol., 1965, 70, 386-393.

Marks, M. R., \& Jack, O. Verbal context and memory span for meaningful materials. Amer. J. Psychol, 1952, 65, 298-300.

Miller, G. A., \& Selfridge, J. A. Verbal context and the recall of meaningful material. Amer. J. Psychol., 1950, 63, 176-185.

Richardson, P., \& Voss, J. F. Replication report: verbal context and the recall of meaningful material. J. exp. Psychol., 1960, $60,417-418$.

Sharp, H. C. Effect of contextual constraint upon recall of verbal passages. Amer. J. Psychol., 1958, 71, 568-572.

Taylor, A., \& Moray, N. Statistical approximations to English and French. Lang. Speech, 1960, 3, 7-10.

\section{Note}

1. The author is indebted to Mr. J. K. Clarkson for his advice, and to Professor $\mathrm{H}$. Kay for providing the facilities for this research. 